\title{
SiM.te
}

\section{Climate Change Impacts on Future Carbon Stores and Management of Warm Deserts of the United States}

\author{
By Michell L. Thomey, Paulette L. Ford, Matthew C. Reeves, Deborah M. Finch, \\ Marcy E. Litvak, and Scott L. Collins
}

\section{On the Ground}

- Reducing atmospheric $\mathrm{CO}_{2}$ through enhanced terrestrial carbon storage may help slow or reverse the rate of global climate change. However, information on how climate change in the Southwest might affect the balance between $\mathrm{CO}_{2}$ uptake and loss on semiarid rangelands is not easily accessible to land managers.

- We summarize studies that focus on key components of carbon exchange across the warm deserts of North America to determine if common trends exist that can be used in management.

- Management strategies that increase carbon sequestration or decrease carbon loss are especially important. Thus managers will need to know what management practices are likely to promote carbon storage or minimize losses during critical time periods.

Keywords: global climate change, carbon dioxide $\left(\mathrm{CO}_{2}\right)$, carbon sequestration in arid-semiarid ecosystems, Mojave Desert, Sonoran Desert, Chihuahuan Desert, land management to increase carbon storage.

Rangelands 36(1):16-24

doi: 10.2111/RANGELANDS-D-13-00045.1

(C) 2014 The Society for Range Management

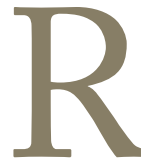

educing concentrations of greenhouse gases (GHG) is a pressing environmental issue that has increased the necessity to quantify the exchange of GHG between terrestrial ecosystems and the atmosphere. Carbon dioxide $\left(\mathrm{CO}_{2}\right)$ is one of the primary anthropogenic greenhouse gases. Reductions in atmospheric $\mathrm{CO}_{2}$ concentration through enhanced terrestrial carbon storage may help slow or reverse the rate of global climate change. ${ }^{1}$ As a result, federal land management agencies, for example the Forest Service and Bureau of Land Management, are now beginning to implement management policies to increase carbon storage.

Throughout the southwestern United States, climate models consistently project increased aridity and seasonal shifts in precipitation, along with more extreme precipitation events. Moreover, recent warming in the Southwest is among the most rapid in the nation. Information regarding how these elements of climate change might affect the balance between $\mathrm{CO}_{2}$ uptake and loss (i.e. flux) is especially lacking in forms available to land managers on semiarid rangelands. Here, we present a brief overview of the wide variety of topics to consider related to the key components of carbon flux, including leaf-level photosynthesis, soil respiration, and plant community productivity across the warm deserts of North America (Fig. 1). ${ }^{2}$ We also provide a discussion of links between management practices and carbon sequestration, as well as the current goals and unique challenges of management in this region. Since desertification is projected to increase in the future, management strategies that increase carbon sequestration or decrease carbon loss will be especially important.

\section{The Terrestrial Carbon Cycle}

Prior to understanding how management actions can alter carbon stores, a baseline assessment is needed to estimate the current amount of carbon being stored in an area. In the terrestrial carbon cycle (Supplemental Material; available online at http://dx.doi.org/10.2111/RANGELANDSD-13-00045.s1), plants take up $\mathrm{CO}_{2}$ from the atmosphere through photosynthesis, and $\mathrm{CO}_{2}$ is released back to the atmosphere as the by-product of autotrophic (plant) and heterotrophic (e.g., microbial) respiration or what is collectively referred to as ecosystem respiration. The rate at which photosynthesis and ecosystem respiration occurs is largely affected 


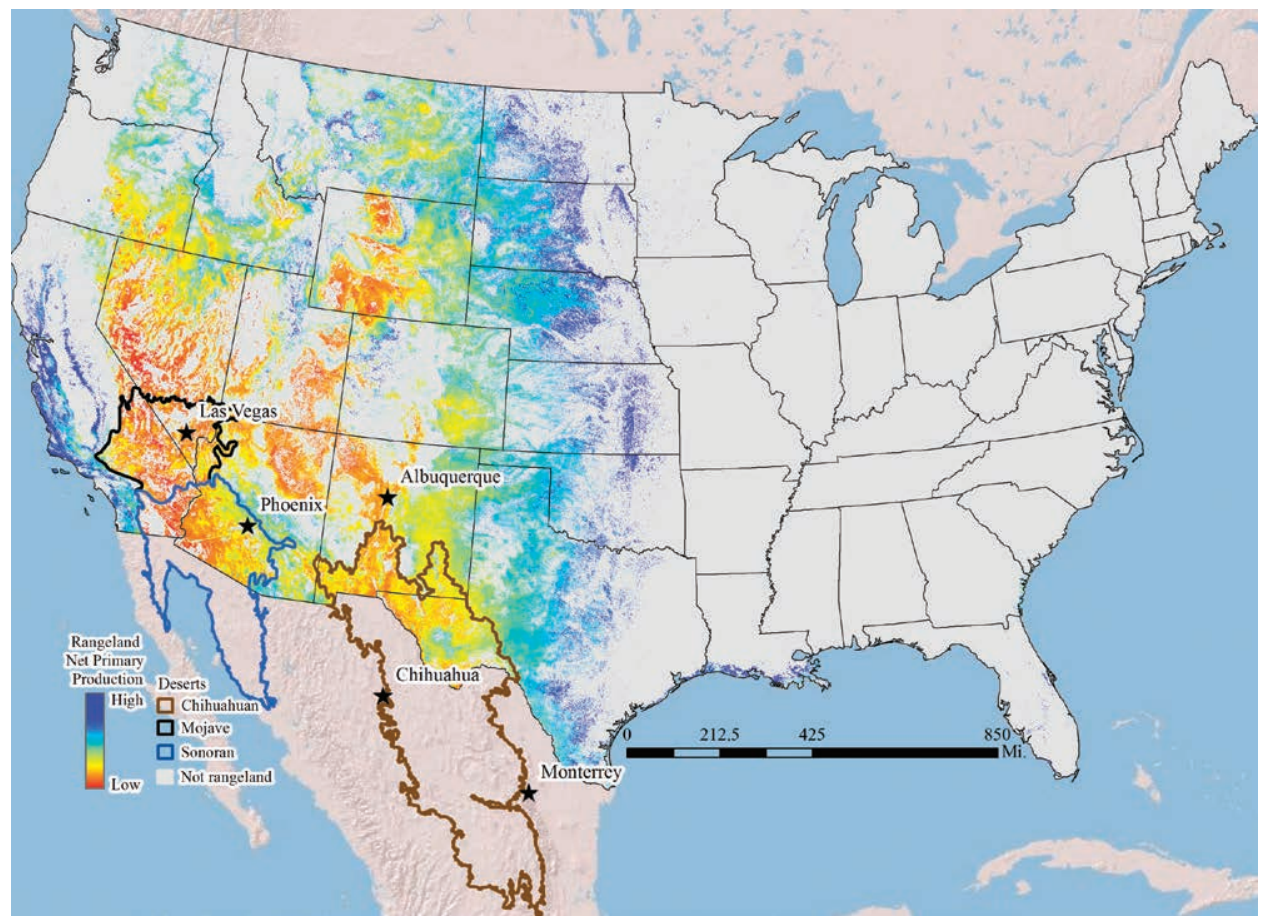

Figure 1. Rangeland net primary production estimated from the Moderate Resolution Imaging Spectroradiometer (MODIS) NPP Collection 4.5 product. ${ }^{2}$ Note the predominantly low net primary production that characterizes deserts.

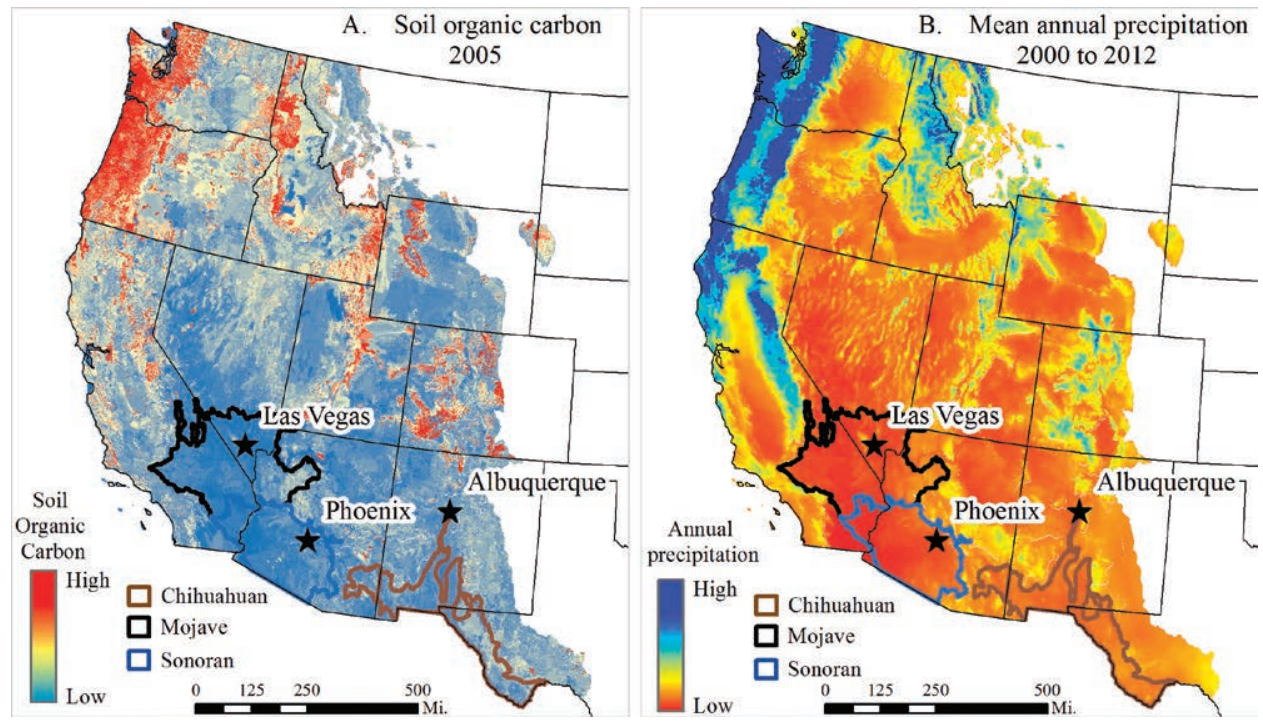

Figure 2. Soil organic carbon adapted from the LANDCARBON Project. ${ }^{3}$ Note the relationship between mean annual precipitation and soil organic carbon. Generally speaking, greater precipitation enables greater rates of carbon accumulation. Mean annual precipitation was generated from the Parameter-elevation Regressions on Independent Slopes Model (PRISM) data Daly et al. ${ }^{4}$ (http://www.prism.oregonstate.edu/). Deserts exhibit both low annual precipitation and low carbon storage ability relative to other biomes.

by precipitation and temperature (Fig. 2). ${ }^{3,4}$ Because of increased $\mathrm{CO}_{2}$ emissions largely through burning of fossil fuels, ecosystems are subject to shifts in climate patterns that will change both soil moisture and temperature. While the degree of impact may vary by latitude, increasing $\mathrm{CO}_{2}$ concentrations, warmer temperatures, and changes in the frequency of extreme weather events will alter the balance between $\mathrm{CO}_{2}$ uptake and $\mathrm{CO}_{2}$ loss, and influence the amount of $\mathrm{CO}_{2}$ remaining in the atmosphere.

Although arid-semiarid regions are characterized by low plant productivity (Fig. 1), they cover approximately $45 \%$ of the world's surface and, therefore, collectively contribute to the global carbon cycle. These regions store an estimated 199 billion metric tons of carbon in vegetation and in soil organic 


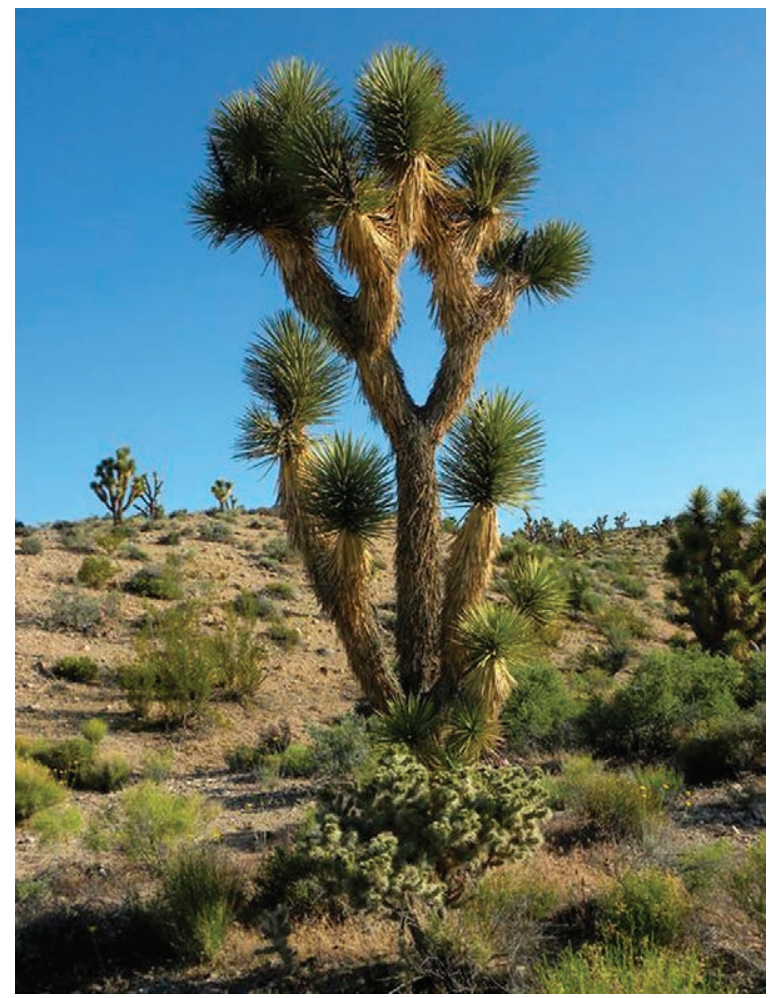

Figure 3. Mojave Desert. Photo courtesy of US Department of the Interior Bureau of Land Management.

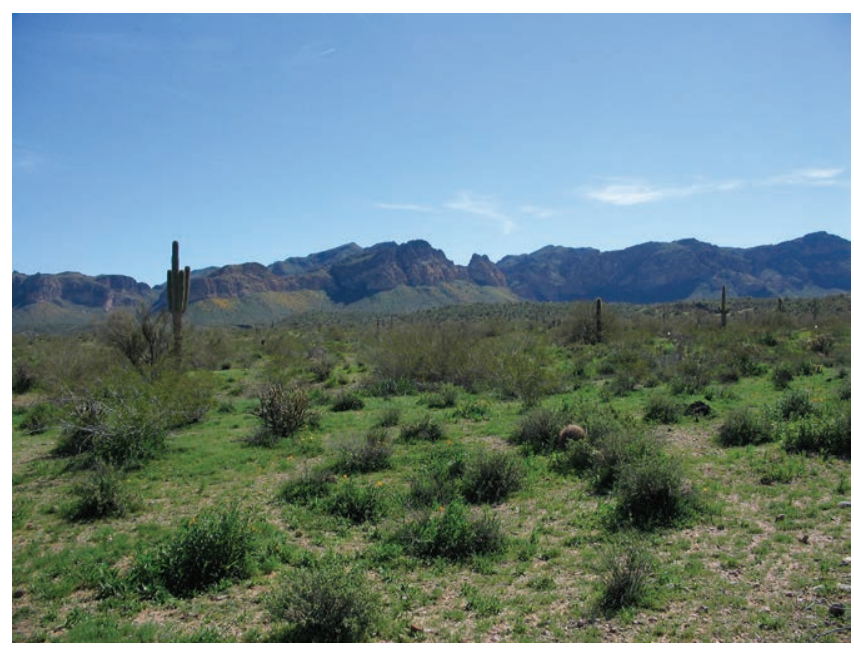

Figure 4. Sonoran Desert. Photo courtesy of Scott Collins.

carbon. Moreover, arid land soils also contain an additional 800-1700 billion metric tons of inorganic carbon primarily as calcium carbonate. For this reason, arid-semiarid soils are considered the third largest global pool of carbon. Inorganic carbon is relatively stable whereas organic carbon can be metabolized releasing $\mathrm{CO}_{2}$. In these water-limited ecosystems, $\mathrm{CO}_{2}$ loss through ecosystem respiration frequently exceeds plant productivity, as net $\mathrm{CO}_{2}$ uptake is limited to periods of favorable rainfall. Arid-semiarid ecosystems are highly responsive to precipitation variability and, therefore, will be affected by predicted increases in extreme precipitation events, increased $\mathrm{CO}_{2}$ concentrations, and increased temperatures.

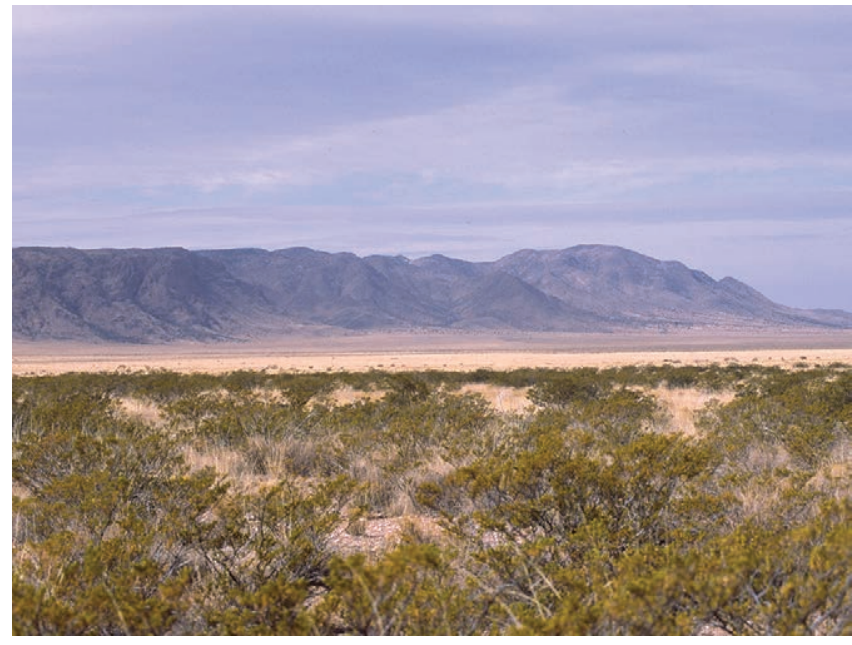

Figure 5. Chihuahuan Desert. Photo courtesy of Scott Collins.

\section{The Warm Deserts of North America}

The warm deserts are divided into three types: 1) Mojave (Fig. 3), 2) Sonoran (Fig. 4), and 3) Chihuahuan (Fig. 5). While the largest areas of the Sonoran and Chihuahuan deserts are located in Mexico (Fig. 1), in the United States these desert types are distributed from Nevada into southern California (Mojave), east through southern Arizona (Sonoran), southern New Mexico (Chihuahuan), and finally into western Texas (Chihuahuan). Droughts and mega droughts are a trait of the regional climate but global climate change could initiate a drying pattern that the southwestern United States has not experienced in thousands of years, leaving these ecosystems unable to recover from such drought events. ${ }^{5}$

The Mojave, Sonoran, and Chihuahuan deserts are located in the rain shadow of the Sierra Nevada, Peninsular and Sierra Madre Occidental, and Sierra Madre Oriental mountain ranges, respectively. Another shared trait is that precipitation is variable and occurs in pulses that trigger activity by living organisms followed by a dry interpulse period when the ecosystem returns to a less biologically active state. Finally, in the southwestern United States, short-term variability in winter rainfall is largely influenced by the El Niño and La Niña phases of the Southern Oscillation. El Niño leads to increased winter precipitation and above-average rainfall across the warm deserts. In contrast, a La Niña leads to dry winters across the warm deserts. The warm deserts are distinguished by differences in their climate. The obvious differences include, 1) the precipitation gradient with rainfall increasing from the Mojave Desert east to the Chihuahaun Desert, and 2) the seasonality of precipitation with a winter dominant rainfall in the Mojave, summer and winter rainfall dominant (bimodal) in the Sonoran, and summer rainfall dominant in the Chihuahuan Desert with some winter precipitation inputs.

The Mojave Desert is the driest of the warm deserts. Average rainfall is $137-168 \mathrm{~mm} / \mathrm{year}$ and most rainfall occurs in winter from October through April. The mean annual temperature range is from $1.5-28.7^{\circ} \mathrm{C}$ and winter snowfall 
can occur. This rainfall pattern is particularly important for the $\mathrm{C}_{3}$ perennial shrubs Joshua tree (Yucca brevifolia, Fig. 3), creosote bush (Larrea tridentata), white bursage (Ambrosia dumosa), desert holly (Atriplex hymenelytra), cattle saltbush (A. polycarpa), and blackbrush (Coleogyne ramosissima) that dominate the landscape.

The Sonoran Desert is the warmest North American desert. Annual temperatures range from $12-30^{\circ} \mathrm{C}$. This desert type rarely experiences freezing temperatures or winter snowfall. It is distinguished, in part, by cold intolerant succulents, such as saguaro (Carnegiea gigantea, Fig. 4). In addition, the Sonoran Desert supports a variety of woody species including palo verde (Cericdium macrophyllum), acacia (Acacia greggii), desert ironwood (Olneya tesota), honey mesquite (Prosopis glandulosa), ocotillo (Fouquieria splendens), and shrubs such as brittlebush (Encelia farinosa), cattle saltbush (Atriplex ploycarpa), and creosote bush. Perennial grasses, e.g., big galleta (Pleuraphis rigida), occupy spaces between shrubs. While rainfall varies across the region, mean annual rainfall is $258-311 \mathrm{~mm} /$ year and occurs in a bimodal pattern that promotes high plant diversity including winter and summer active species.

The Chihuahuan Desert is located at the wettest end of the precipitation gradient. On average, annual precipitation is $250 \mathrm{~mm} /$ year $(77-507 \mathrm{~mm} /$ year $)$ and the mean annual temperature is $14.7^{\circ} \mathrm{C}\left(13.5-16.3^{\circ} \mathrm{C}\right)$. This desert occurs at higher elevations and in cooler temperatures compared to the Mojave and Sonoran Deserts. The majority ( 60\%) of precipitation in this region falls during the summer monsoon (July-September), but winter rainfall and snowfall results in a weak bimodal signal. These climate factors contribute to dominance by perennial $\mathrm{C}_{4}$ grasses including black grama (Bouteloua eriopoda, Fig. 5), sacaton (Sporobolus spp.), galleta (Pleuraphis jamesii), muhly (Mublenbergia spp.), and purple three-awn (Aristida purpurea). Other dominant plant species are creosote bush, broom snakeweed (Gutierrezia sarothrae), and longleaf jointfir (Ephedra trifurca).

\section{Carbon Cycling in the North American Warm Deserts \\ Precipitation}

Throughout the warm deserts, most rainfall events are $\leq 5$ $\mathrm{mm}$ and, therefore, primarily increase microbial activity and $\mathrm{CO}_{2}$ emission to the atmosphere (Fig. 2) (Supplemental Material; available online at http://dx.doi.org/10.2111/ RANGELANDS-D-13-00045.s1). Rainfall events $>10$ $\mathrm{mm}$ are required for plant productivity to exceed ecosystem respiration. In the Sonoran and Chihuahuan deserts there is consistently a two-to-three-day lag following a rainfall event before plant productivity surpasses ecosystem respiration losses. ${ }^{6,7}$ The delayed increase in the balance between $\mathrm{CO}_{2}$ uptake and loss may also vary due to differences in soil moisture and the growing season.

Regardless of plant community structure, the variability in the balance between $\mathrm{CO}_{2}$ uptake and loss is mostly driven by large rainfall events. This trend is easily recognized in the Mojave Desert where deep-rooted shrubs are dominant but is less obvious in desert grasslands where the majority of roots are located in the top $30 \mathrm{~cm}$ of the soil. Nevertheless, research indicates that a significant increase in photosynthesis of the dominant Chihuahuan Desert grass black grama in response to small $(5 \mathrm{~mm})$ rainfall events does not always translate into a significant increase in plant productivity or change the balance between $\mathrm{CO}_{2}$ uptake and loss. ${ }^{8}$

Another factor that contributes to the variability in the balance between $\mathrm{CO}_{2}$ uptake and loss is leaf area. For example, plant productivity is constrained by leaf area and plant density in Chihuahuan Desert grassland. The variability in the balance between $\mathrm{CO}_{2}$ uptake and loss across the warm deserts is attributed to large precipitation events that extend periods of soil water availability leading to improved leaf area and net $\mathrm{CO}_{2}$ uptake. Although water is the most limiting resource in desert ecosystems, a threshold exists such that precipitation pulses may initiate photosynthesis and limited plant growth but net $\mathrm{CO}_{2}$ uptake does not surpass ecosystem respiration.

In addition to pulse size, pre-existing soil moisture along with the seasonal timing of rainfall affects $\mathrm{CO}_{2}$ uptake. In the Sonoran Desert, the magnitude of the response of photosynthesis was greater when water was added to dry soil compared to wet soils where desert grasses had already reached their physiological capacity. ${ }^{9}$ The difference in soil moisture is also reflected in the balance between $\mathrm{CO}_{2}$ uptake and loss but for different reasons. For example, $\mathrm{CO}_{2}$ uptake was enhanced when a large rainfall event occurred following a premonsoon season drought. The response of $\mathrm{CO}_{2}$ uptake to the seasonal timing of rainfall is partially a function of the dominant plant type. For example, desert grassland plant productivity is strongly correlated with summer (August) precipitation, while desert shrubland plants may respond to both summer and winter precipitation. ${ }^{10}$ This affects the balance between $\mathrm{CO}_{2}$ uptake and loss in several ways, but generally, soil moisture and seasonal patterns of precipitation affect plant and microbial response and drive the variability in the balance between $\mathrm{CO}_{2}$ uptake and loss.

\section{$\mathrm{CO}_{2}$ and Warming}

It is projected that arid-semiarid ecosystems will be responsive to elevated $\mathrm{CO}_{2}$, but the impact of increased atmospheric $\mathrm{CO}_{2}$ concentrations will vary with soil moisture and among ecosystems. The most intensive experiment to study the response of arid ecosystems to elevated $\mathrm{CO}_{2}$ occurred in the Mojave Desert at the Nevada Desert Free-Air $\mathrm{CO}_{2}$ Enrichment Facility. Based on results from this experiment, it appears an increase in atmospheric $\mathrm{CO}_{2}$ concentrations in arid ecosystems may enhance carbon sequestration but only in years with above-average rainfall. However, increased primary productivity due to higher $\mathrm{CO}_{2}$ and soil moisture can only be sustained with continued availability of soil nitrogen.

In addition to precipitation and $\mathrm{CO}_{2}$, warmer temperatures can directly affect plant productivity and respiration or indi- 
rectly affect carbon balance by altering soil moisture, nitrogen availability, and species composition. In an analysis from 85 warming studies established around the globe, it was found that warming generally stimulated plant growth, respiration, and $\mathrm{CO}_{2}$ uptake and loss. Unfortunately, desert ecosystems are rarely included in warming studies. However, we would expect that warmer temperatures alone would intensify soil water limitation and therefore decrease respiration and plant productivity, but these responses may vary depending on the vegetation.

In Chihuahuan Desert shrublands, one experimental study (Fig. 6) found that by reducing the daily range of soil temperature, soil moisture and soil respiration increased and nitrogen availability decreased, while photosynthesis of creosote bush was not affected. Warmer minimum nighttime air temperatures had an opposite effect on vegetation cover in Chihuahuan Desert grassland. A $2.5^{\circ} \mathrm{C}$ increase in minimum nighttime air temperatures significantly increased cover of the Chihuahuan Desert grass black grama, and of the shrub broom snakeweed, while warmer temperatures did not affect blue grama (Bouteloua gracilis) cover. ${ }^{11}$ Also in the Chihuahuan Desert grassland, it was found that while bacterial response tracked precipitation, soil temperature was the major determinant of fungal carbon use. Since community composition and microbial activity are sensitive to warmer temperatures in arid ecosystems, additional research is needed to fully understand how this element of climate change may reshape these communities.

\section{Disturbance}

Many environmental hurdles limit our ability to increase carbon sequestration in arid-semiarid ecosystems. These barriers alter the carbon cycle, are often exacerbated by climate change, and will affect the options available to land managers to enhance carbon sequestration. In general, fire and grazing can affect ecosystems through a variety of mechanisms that act on components of the carbon cycle. For example, both grazing and grazing exclusion have been found to promote shrub encroachment in Sonoran and Chihuahuan desert grasslands. The change in species composition from grassland to shrubland would be expected to affect spatial variability of soil organic carbon through changes in aboveground and belowground plant growth, and nitrogen availability especially if the shrub was a legume, such as mesquite. Emerging evidence in the northern Chihuahuan Desert suggests that creosote bush shrublands provide a larger carbon sink than the black grama grasslands they are invading.

Similarly, climate change is likely to increase fire frequency in the southwest and this may facilitate a change in species composition by invasive species or be perpetuated by the presence of invasive grasses across the warm deserts. At the continental-scale, shrub encroachment into Chihuahuan Desert grassland results in lower plant productivity compared to mesic sites where shrubs have invaded. These differences in primary productivity and soil respiration in response to shrub encroachment stand to alter the source-sink strength of some desert ecosystems.
Invasive Species

Across the Mojave, Sonoran, and Chihuahuan deserts, high temperatures, limited water availability, and nutrient-deficient soils create an environment where a specific suite of native plants persists. However, increasing $\mathrm{CO}_{2}$ concentrations, precipitation variability, and increasing nitrogen deposition modify the availability of limiting resources and may increase the abundance of invasive species in arid-semiarid ecosystems. For example, when grown at elevated $\mathrm{CO}_{2}$ concentrations, plant density, biomass, and seed rain were significantly higher in the nonnative annual red brome (Bromus madritensis ssp. Rubens) compared to native annuals during a wet year in the Mojave Desert. ${ }^{12}$ The favorable response of red brome is attributed to a decrease in the energetic cost of aboveground biomass construction under elevated atmospheric $\mathrm{CO}_{2}$ concentrations. Another study found that the nonnative annual species Arabian schismus (Schismus spp.) increased in density, and Asian mustard (Brassica tournefortii) allocated more resources to seed production in response to disturbance as well as supplemental watering. ${ }^{13}$ This indicates that invasive species establishment in desert ecosystems is also favored by multiple aspects of climate change.

\section{Carbon Sequestration and Storage Defined}

A large portion of carbon resides in soils of arid-semiarid ecosystems. Carbon pools contained in the soil emanate from both organic and inorganic sources. Given that most management techniques are administered to influence vegetation, it follows that the rate of organic carbon accumulation is directly influenced by management actions. As a result, in this section we focus primarily on soil organic carbon, which is directly influenced by management activities.

Prior to understanding how management actions can alter carbon stores or to developing a monitoring proto$\mathrm{col}$, a baseline assessment is needed to estimate the current amount of carbon being stored in an area. Since far more carbon is stored belowground rather than aboveground it follows that any baseline assessment should include a substantial focus on belowground carbon pools. Creating a baseline assessment of carbon stocks on rangelands poses unique challenges. Unlike forested landscapes, few agency standards or resources exist for collecting information on nonforest environments. In addition, a greater proportion of carbon is stored belowground in rangelands compared with forests or woodlands thereby requiring expensive soil analyses for quantifying baseline carbon stores. Methods for estimating carbon stores can be categorized as direct measures, indirect measures, and modeling. Each category includes advantages and disadvantages and varying levels of cost, complexity, and accuracy.

\section{Measuring Stored Carbon}

Simple laboratory measurements for soil carbon such as dry combustion or bulk density testing and a variety of field techniques involving remote sensing are available. Pres- 
ently the USDA Natural Resources Conservation Service (NRCS) is systematically measuring soil carbon using fieldbased remote sensing methods. Other federal land management agencies could use a similar approach to help fulfill their obligations to implement management policies to increase carbon storage. ${ }^{14}$

Although most carbon resides belowground as soil organic carbon, some rangeland ecosystems exhibit a substantial amount of carbon stored aboveground in shrubs. Aboveground carbon stores are not always considered in sequestration studies due to the relative ease with which shrubs can disappear from a plant community. Nevertheless, many stands support significant aboveground carbon stores that are important to evaluate when a full accounting of carbon stocks is required. Inventorying and monitoring aboveground carbon stocks can easily be achieved using destructive sampling or allometric equations (e.g. Means et al. ${ }^{15}$; BIOPAK Software ${ }^{i}$ ) relating stand structure to biomass components. Once a baseline assessment of carbon stores has been conducted, monitoring can be used to evaluate changes in carbon stocks through time.

\section{Monitoring}

Monitoring changes in carbon stores is critical to determining the positive and negative impacts of various types and levels of landscape treatments and disturbance regimes. Monitoring carbon stocks in rangeland ecosystems is inherently difficult because the change in mass of carbon is small relative to the total amount of carbon stored. It can take years or decades before significant trends emerge.

Soil organic carbon is often monitored using a combination of field and laboratory measures, indirect observations such as remote sensing, and ecosystem modeling. Properly calibrated simulation models such as Comet-VR ${ }^{\mathrm{ii}}$ provide a suitable framework for estimating the effects of disturbances and land management techniques on carbon stores of rangelands. The most common rangeland management practices which have a meaningful impact on soil organic carbon include fire and grazing. The effect of these practices on carbon stores and rates of sequestration are often interlinked, confounding, and poorly understood across the wide range of nonforest ecosystems.

\section{Management and Policy Implications}

Carbon storage is a critical ecosystem service controlled by interactions between climate and anthropogenic factors. ${ }^{16}$ Oftentimes, however, managers and policy makers incorrectly assume that managing, or even estimating, carbon stores is a straightforward process. Several primary factors make measuring and monitoring soil carbon across meaningful spatial

\footnotetext{
iFor more information on BIOPAK Software, see http://andrewsforest. oregonstate.edu/data/tools/software/biopak.cfm?topnav=149.

ii For more information on Comet-VR, see http://www.cometvr.colostate. edu/.
}

and temporal scales exceedingly difficult, especially in arid environments.

Most soils in arid environments include large quantities of inorganic carbon components (carbonates) and much smaller pools of organic carbon. With regard to organic carbon, xeric rangelands tend to be in carbon balance over the long term. They may be small carbon sources or sinks over short time periods depending on environmental conditions, particularly monsoon rainfall. This fact requires managers to thoughtfully consider management practices that do not impede sequestration during critical times, such as the monsoon season, when sequestration may occur. What's more, when a site acts as a sink, the annual addition of carbon to the soil is very small relative to the total stored carbon pool, so specialized procedures and highly calibrated equipment are required for accurate measurement of incremental carbon sequestration. In addition, because carbon pools change slowly, long time periods are needed to detect meaningful differences in soil carbon content that may result from various management approaches. The extreme spatial and temporal variability of landscapes in warm deserts suggests intensive sampling and monitoring are required to accurately measure $\mathrm{CO}_{2}$ uptake. This costly endeavor limits our understanding of management and climate change on carbon storage in warm deserts.

While grasslands and forests have much higher levels of organic carbon, arid and semiarid lands contain the majority of inorganic carbon within the first meter of soil accounting for about $90 \%$ of the total carbon content in the region. These inorganic compounds can confound measures of $\mathrm{CO}_{2}$ uptake, especially in arid environments where rates of productivity are exceedingly low, making detection of significant differences through time difficult. The fate of these inorganic compounds resulting from climate change is uncertain. Under most conditions this inorganic carbon is safely sequestered and nearly all of the carbon that is respired by these soils is from organic sources. If land degradation and desertification increase regionally, however, increased rates of erosion could result, which may ultimately expose deeper soil horizons and create dissolution of stored inorganic soil carbonates.

Increased precipitation variability will substantially affect the capacity of these water-limited ecosystems to exploit increased atmospheric $\mathrm{CO}_{2}$ concentrations. Clearly climate change mitigation, via increased carbon sequestration, in arid-semiarid ecosystems has a low potential when compared with more productive ecosystems. However, because aridsemiarid systems cover about $45 \%$ of the terrestrial surface, management strategies that increase carbon sequestration or decrease carbon loss are worth consideration.

Among the elements of climate change, precipitation variability is the least predictable but remains the most influential component in arid-semiarid ecosystems. Consequently, the most beneficial and cost-effective land management strategies should 1) work to restore degraded lands to improve their potential for storing atmospheric $\mathrm{CO}_{2}$, and 2) maximize carbon gain during peak periods of productivity. 


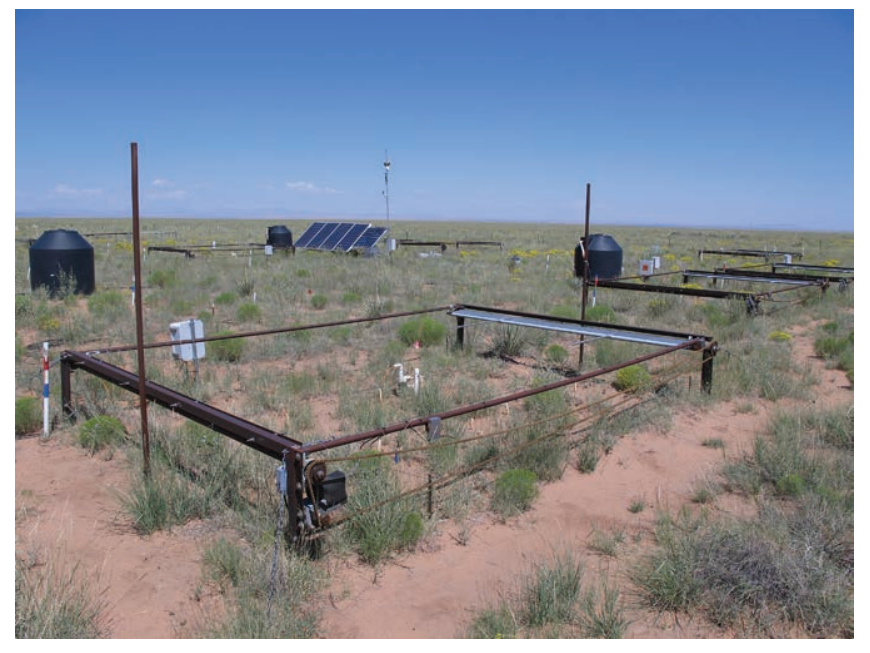

Figure 6. Nighttime warming experiment at the Sevilleta National Wildlife Refuge, New Mexico. This long-term experiment is designed to determine the effects of warmer nighttime temperatures on carbon fluxes in native desert grassland. Photo courtesy of Scott Collins.

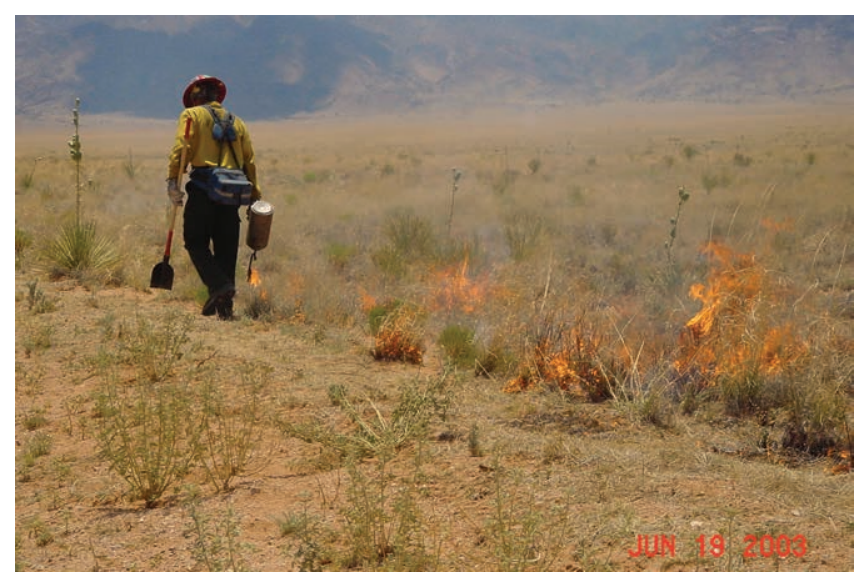

Figure 7. Controlled burn in Chihuahuan Desert grassland at the Sevilleta National Wildlife Refuge, New Mexico. Photo courtesy of US Fish and Wildlife Service.

\section{The Climate Change Scorecard}

The USDA Forest Service (USFS) developed the National Roadmap for Responding to Climate Change, ${ }^{\mathrm{iii}}$ and plans to respond to climate change in three interconnected ways: 1) Assess current risks, vulnerabilities, policies, and gaps in knowledge; 2) Engage employees and stakeholders to seek solutions; and 3) Manage for resilience, in ecosystems as well as in human communities, through adaptation, mitigation, and sustainable consumption strategies. The USFS is using the Climate Change Scorecard (CCS) to track progress on this Roadmap. Element Nine of the CCS addresses carbon sequestration and provides fundamental questions for managers to address when reporting on their accomplishments towards developing land management strategies in the context of climate change.

iii To learn more about the National Roadmap for Responding to Climate Change, see http://www.fs.fed.us/climatechange/pdf/Roadmapfinal. pdf.

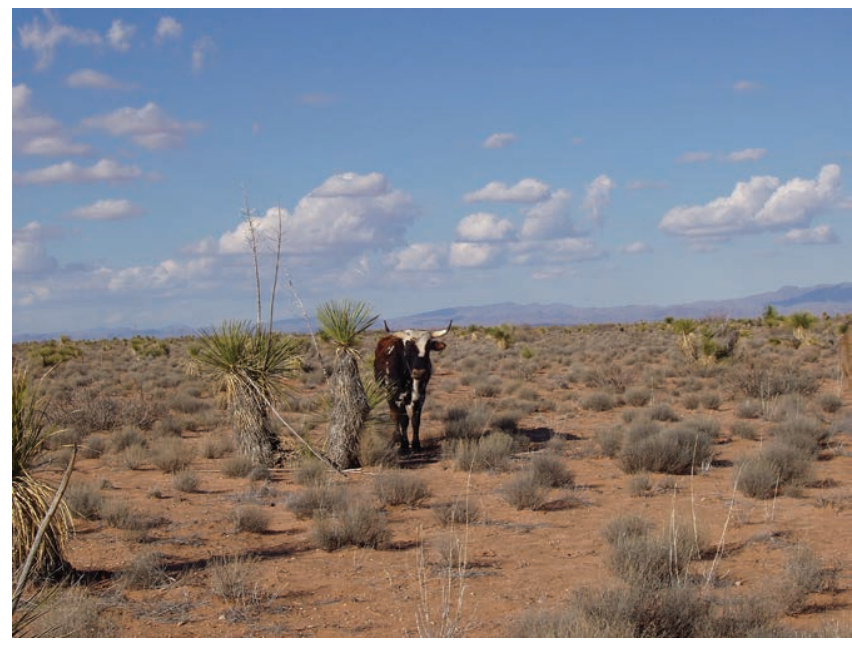

Figure 8. A lone steer grazing in Chihuahuan Desert on the Jornada Experimental Range in southern New Mexico. Photo courtesy of Scott Collins.

The scorecard defines the required baseline assessment of carbon stocks including the consideration of management practices to increase carbon sequestration or reduce emissions. The scorecard evaluation process contains provisions for developing a baseline assessment of carbon stocks, understanding how management practices and disturbances influence carbon stocks, sequestration and emissions, and balancing carbon stewardship with the management of other benefits. These provisions are linked to complicated biological processes which are often poorly understood and represented by confounding research. There are, however, helpful guidelines and generalizations that can be made. In the following section, we provide an overview of how management practices may influence carbon sequestration. Specifically we focus on fire and grazing as management tools because these are the most common management practices (Figs. 7 and 8).

\section{Effects of Management Actions}

Fire in most nonforest systems has the obvious effect of reducing aboveground stores of carbon. However, beyond the initial and obvious response, the effects of fire on carbon sequestration on nonforest landscapes are complicated to quantify. Fires can change plant diversity and structure through changes in the availability of light, water, and nutrients. Such alterations in ecosystem structure and physical environment often modify primary productivity, and nutrient fluxes that subsequently alter carbon storage in plants and soils. The direction and magnitude of these changes, however, depend on vegetation type, fire frequency, fire duration, and season of fire occurrence.

Sustaining carbon uptake relies on growth and development of vegetation, which requires careful balance with grazing that affects carbon sequestration. For example, in more mesic areas grazing can increase soil organic carbon, but net primary production can decrease as a result of altered species composition. In arid systems, heavy stocking rates greatly 


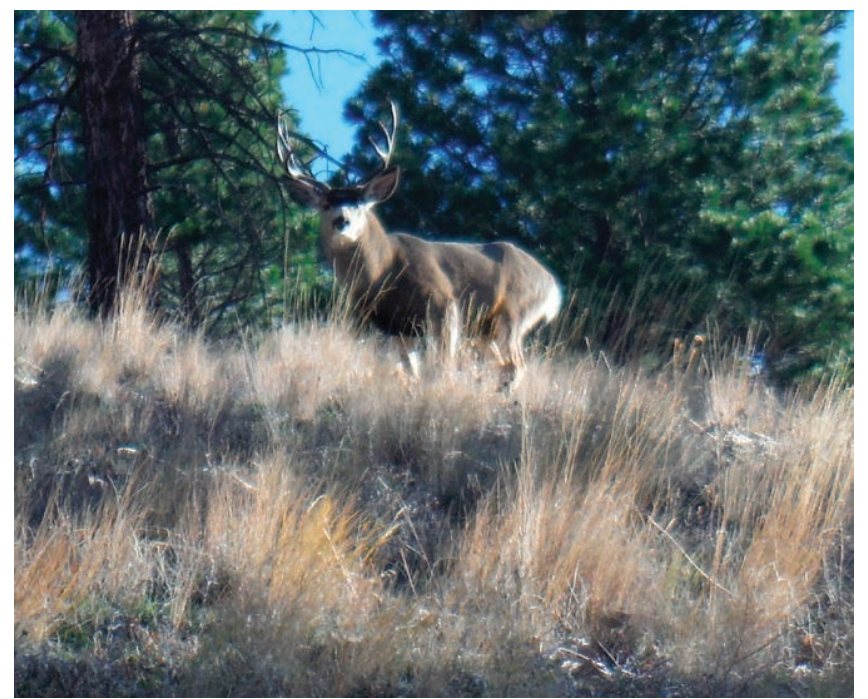

Figure 9. A male mule deer (Odocoileus hemionus). Photo courtesy of Matt Reeves.

reduce grass abundance and thus the mass of fine roots of grasses. Should forbs increase, this would also lead to less carbon going belowground in roots. When heavy grazing is coupled with sustained or severe drought, significant losses of soil organic carbon can occur.

\section{Balancing Carbon Sequestration With Other Services}

Carbon sequestration and storage (Supplemental Material; available online at http://dx.doi.org/10.2111/RANGELANDSD-13-00045.s1), as a GHG mitigation strategy, can be viewed as an ecosystem service. Management actions influencing carbon storage and emissions must ultimately be balanced with the need to sustainably produce other goods and services such as wildlife habitat, livestock, clean air and water, aesthetic properties, and other natural amenities. Addressing this need requires both the art and science of range management, in addition to more comprehensive research aimed at understanding tradeoffs between carbon storage and other products or services.

In many cases, production of multiple goods and services can be simultaneously enhanced through proper management techniques. For example, nutrient cycling, forage, biotic integrity, biodiversity, and carbon sequestration can be enhanced or maintained through removal of some invasive species. In contrast to this type of win-win scenario, tradeoffs between various management outcomes will depend on resource values and sometimes produce one-sided outcomes. As an example, consider the tradeoff between increased carbon capture and storage versus water abundance and availability. In some regions, simply aiding the spread and rate of encroachment by shrubs, such as juniper or mesquite, can capture more carbon. However, in the Chihuahuan Desert, shrub encroachment leads to lower biodiversity, higher regional temperatures, increased surface runoff and erosion, and lowered water tables that could ultimately lower the amount of available surface water.
The relative value of various goods and services in the future will likely respond to our changing climate. The magnitude of these changes in value, however, is subject to public perceptions, along with other environmental, politi$\mathrm{cal}$, and socioeconomic factors. Thus it is conceivable that, in the future, carbon capture and storage may be less of a priority in some ecosystems compared to a dependable supply of clean water, or open space or winter range for ungulates (Fig. 9).

Clearly, balancing societal needs and desires with ecological constraints is not easy. The added consideration of carbon storage creates a multidimensional problem for which decision support systems may be invoked to understand tradeoffs between the potential actions by managers. In this regard, the Integrated Social, Economic, and Ecologic Conceptual Framework (ISEEC) model created by the Sustainable Rangeland Roundtable enables assessment of tradeoffs and implication of management decisions in a multidimensional manner. The likelihood of public land management agencies like the Forest Service or Bureau of Land Management achieving carbon storage planning goals will be increased by use of decision support systems capable of integrating simultaneous multidimensional analysis.

See Thomey et al., 2014 for a technical review of climate change impacts on future carbon stores and management of warm deserts of the United States. ${ }^{17}$ For a detailed bibliography from this article see the online supplemental material at http://dx.doi.org/10.2111/RANGELANDS-D-13-00045.s1.

\section{Acknowledgments}

We thank Jesse Nippert for providing comments to the dissertation chapter, and Linda Joyce, Carly Woodlief, and an anonymous reviewer for comments or reviews.

\section{References}

1. Powlson, D. S., A. P. Whitmore, and K. W. T. Goulding. 2011. Soil carbon sequestration to mitigate climate change: a critical re-examination of the true and the false. European Journal of Soil Science 62:42-55.

2. Running, S. W., R. R. Nemani, F. A. Нeinsch, M. Zhao, M. Reeves, and H. Hashimoto. 2004. A continuous satellite-derived measure of global terrestrial primary production. BioScience 54:547-560.

3. Zhu, Z. and B. C. Reed [eds.]. 2012. Baseline and projected future carbon storage and greenhouse-gas fluxes in ecosystems of the western United States. Reston, VA, USA: US Geological Survey Professional Paper 1797. 192 p. (Also available at: http:// pubs.usgs.gov/pp/1797/.) Accessed 20 January 2014.

4. Daly, C., G. H. Taylor, W. P. Gibson, T. W. Parzybok, G. L. Johnson, And P. PAsteris. 2001. High-quality spatial climate data sets for the United States and beyond. Transactions of the American Society of Agricultural Engineers 43:1957-1962.

5. Fawcett, P. J., J. P. Werne, R. S. Anderson, J. M. Heikoop, E. T. Brown, M. A. Berke, S. J. Smith, F. Goff, L. DonohooHurley, L. M. Cisneros-Dozal, S. Schouten, J. S. Sinnenge 
Damsté, Y. Huang, J. Toney, J. Fessenden, G. Woldegabriel, V. Autdorei, J. W. Geissman, and C. D. Allen. 2011. Extended megadroughts in the southwestern United States during Pleistocene interglacials. Nature 470:518521.

6. Kurc, S. A., and S. E. Small. 2007. Soil moisture variations and ecosystem-scale fluxes of water and carbon in semiarid grassland and shrubland. Water Resources Research 43:W06416. doi:10.1029/2006WR005011.

7. Scott, R. L., E. P. Hamerlynck, G. D. Jenerette, M. S. Moran, and G. A. Barron-Gafford. 2010. Carbon dioxide exchange in a semidesert grassland through droughtinduced vegetation change. Journal of Geophysical Research doi:10.1029/2010JG001348.

8. Thomey, M. L., S. L. Collins, R. Vargas, J. E. Johnson, R. F. Brown, D. O. Natvig, and M. T. Friggins. 2011. Effect of precipitation variability on net primary production and soil respiration in a Chihuahuan Desert grassland. Global Change Biology 17:1505-1515.

9. Ignace, D. D., T. E. Huxman, J. F. Welztin, and D. G. Williams. 2007. Leaf gas exchange and water status responses of a native and non-native grass to precipitation across contrasting soil surfaces in the Sonoran Desert. Oecologia 152:401-413.

10. Sponseller, R. A., S. J. Hall, D. Huber, N. B. Grimm, J. P. Kaye, C. Clark, and S. L. Collins. 2012. Variation in monsoon precipitation drives patterns of Larrea tridentata growth in the upper Sonoran Desert. Functional Ecology 26:750-758.

11. Collins, S. L., J. E. Fargione, C. L. Crenshaw, E. Nonaka, J. R. Elliot, Y. Xia, and W. T. Pockman. 2010. Rapid plant community responses during the summer monsoon to nighttime warming in a northern Chihuahuan Desert grassland. Journal of Arid Environments 74:611-617.

12. Smith, S. D., T. E. Huxman, S. F. Zitzer, T. N. Charlet, D. C. Housman, J. S. Coleman, L. K. Fenstermaker, J. R. SeeMANN, AND R. S. Nowak. 2000. Elevated $\mathrm{CO}_{2}$ increases productivity and invasive species success in an arid ecosystem. Nature 408:79-82

13. Derner, J. D., And G. E. Schuman. 2007. Carbon sequestration and rangelands: a synthesis of land management and precipitation effects. Journal of Soil and Water Conservation 62:77-85.

14. Suarez, D. L. 2006. Inorganic carbon: land use impacts. Encyclopedia of Soil Science 10:895-597.

15. Means, J. E., H. A. Hansen, G. J. Koerper, P. B. Alaback, AND M. W. KLopsch. 1994. Software for computing plant biomass-BIOPAK users guide. General Technical Report PNWGTR-340. Portland, OR, USA: US Department of Agriculture, Forest Service, Pacific Northwest Research Station. 184 p.

16. Suazo, A. A, J. E. Spencer, E. C. Engel, and S. R. Abella. 2012. Responses of native and non-native Mojave Desert winter annuals to soil disturbance and water additions. Biological Invasions 14:215-227.

17. Thomey, M. L., P. L. Ford, M. C. Reeves, D. M. Finch, M. E. Litvak, and S. L. Collins. 2014. Review of climate change impacts on future carbon stores and management of warm deserts of the United States. General Technical Report RMRS-GTR-316. Fort Collins, CO, USA: US Department of Agriculture, Forest Service, Rocky Mountain Research Station. $26 \mathrm{p}$.

Authors are Postdoctoral Fellow, Dept of Biology, University of New Mexico, Albuquerque, NM 87131, USA (Thomey); Research Ecologist, USDA Forest Service, Rocky Mountain Research Station, Albuquerque, NM 87102, USA, plford@ fs.fed.us (Ford); Research Ecologist, USDA Forest Service, Rocky Mountain Research Station, Missoula, MT 59802, USA (Reeves); Program Manager, USDA Forest Service, Rocky Mountain Research Station, Albuquerque, NM 87102, USA (Finch); Associate Professor (Litvak) and Regent's Professor (Collins), Dept of Biology, University of New Mexico, Albuquerque, NM 87131, USA. Funding in support of this research was provided by grants from the USDA Forest Service, Western Wildland Environmental Threat Assessment Center, USDA Forest Service National Fire Plan, and the Sevilleta LTER. This research was completed in partial fulfillment of the requirements for the degree of Doctor of Philosophy from the University of New Mexico. 